\title{
Learning material in compliance with the Revised National Curriculum Statement: a dilemma
}

\author{
Bertus van Etten and Kosie Smit \\ Fontys University, the Netherlands, and Stellenbosch University \\ Email: n.van.etten@concepts.nl and jhs@sun.ac.za
}

\begin{abstract}
This paper reports on the challenges confronting a developer of mathematics learning material according to the Revised National Curriculum Statement of South Africa. The material development is based on the approach to learning embodied in Realistic Mathematics Education in the Netherlands. It is a real challenge to realise the learning outcomes and assessment standards in the South African curriculum and simultaneously to explore learners' informal strategies to come up with their 'own' solutions to practical problems and thus to experience mathematics as real, relevant and enjoyable.
\end{abstract}

\section{Introduction}

When a new curriculum is implemented, a clearly spelled out theory of learning should underpin the process. In spelling out the intended outcomes of the Revised National Curriculum Statement (RNCS), Grades R - 9 (Department of Education, 2002), the creators of the new curriculum did in broad terms give a perspective on the theory of learning they endorse. This includes a statement such as: "The outcomes encourage a learnercentred and activity-based approach to education" (Department of Education, 2002: 1). Understandably, a generic document such as this one cannot be expected to present a detailed theory of learning for a specific subject such as mathematics. However, as a result, there are considerable differences of approach among the people who have to concretise this curriculum on the ground the government officials, material developers, textbook editors, teacher trainers, teachers, etc.

In our opinion, Realistic Mathematics Education, which has been developed in the Netherlands over the past 35 years, offers an approach to the learning of mathematics that enhances the realisation of the RNCS. This approach entails, among other things, a process of "guided reinvention" and "progressive mathematisation" (Freudenthal, 1973; Gravemeijer, 1994; 1998). Drijvers (2003: 52) describes this as follows:

According to the reinvention principle, students should be given the opportunity to experience a process similar to that by which a given mathematical topic was invented. Thus a route has to be designed that allows the students to develop 'their own' mathematics. This process, however, needs guidance from the teacher, to help to further develop sensible directions, to leave 'dead-end streets' and to ascertain convergence towards the common standards within the mathematics community. The point of departure for this process is the informal strategies that students come up with that gradually develop into more formalised methods.

As far as the selection of subject matter is concerned, Gravemeijer explains that "the subject matter that is to be mathematised should be experientially real for the students" (Gravemeijer, 1998: 277). "These may be everyday situations, but they may also be fantasy worlds in which the students can immerse themselves. And - last but not least - it may be mathematics that is experientially real" (Gravemeijer, 1998: 287); "the core principle is that mathematics can and should be learned on one's own authority and through one's own mental activities" (Gravemeijer, 1998: 277). Only at the end of the mathematising process is a concept/definition/result refined to a more formal format, usually with guidance of the teacher.

On the basis of this approach the authors have over the past few years been experimenting with learning material for the senior phase. We have chosen Realistic Mathematics Education as our vehicle to meet the challenges in the mathematics classroom.

\section{The Brave Maths Mouse Project}

The first author has since 2004 spent two periods of three months each in project schools of the socalled Brave Maths Mouse Project to observe the activities in the senior phase mathematics classrooms of a few historically disadvantaged 
schools. These observations have significantly influenced the opinions expressed in this paper.

Features of the schools, teachers and learners when the project was initiated, are summarised below.

- The language of instruction is the mother tongue of the learners.

- The level of numeracy and literacy of a large percentage of learners is well below the level accepted in the curriculum. Many learners entering the senior phase have not achieved the outcomes of the intermediate phase.

- The differences occurring in a class can be considerable. Certain learners in grade 7 cannot read. In the same class one finds a learner who does not know what the answer to 18 divided by 6 is, while another is proficient in the use of tables, can read fluently and measure and construct accurately.

- The teachers in general follow one strategy of instruction, viz. to show the learners a mathematical recipe and to let them practise it. The teacher does the talking, while the learners have little opportunity to discuss the material.

- The learners are accustomed to waiting for instructions. They are unfamiliar with the idea of taking responsibility for their own learning.

- Learners do not have their own textbooks. Much time is lost in copying from the black board.

- There is a shortage of set squares, compasses and pocket calculators in the class. The teacher also does not have drawing instruments for the black board.

- Domestic circumstances often prevent learners from doing homework.

Our objective has been to develop learning material for grades 7 to 9 in order to realise the mathematics objectives of the curriculum that are relevant for these learners. Our strategy with the learner modules is that each learner receives her/his own copy and has to interact with the text, individually as well as in a group context. The teachers receive guidance on their role as facilitators of the learning process and as guides towards the acquisition of more structured mathematical expertise.

On the basis of our experience we try in this paper to illustrate the difficulties we have encountered in choosing learning material that complies with the curriculum and links with the level of knowledge of these learners and teachers. We present examples of learner material to illustrate and motivate our point of view.

\section{Learning Outcome 2: patterns, functions and} algebra

The curriculum specifies:

In the Senior Phase the focus of Learning Outcome 2 is to formalise the rules generating patterns. The learner should continue to:

- investigate numerical and geometric patterns to establish the relationships between variables; and

- express rules governing patterns in algebraic language or symbols.

(Department of Education, 2002: 63)

One of the corresponding assessment standards for grade 9 specifies:

We know this when the learner constructs mathematical models that represent, describe and provide solutions to problem situations, showing responsibility towards the environment and the health of others (including problems within human rights, social, economic, cultural and environmental contexts). (Department of Education, 2002: 74)

For the author of a textbook it is not a straightforward task to translate this learning outcome and the accompanying assessment standards into concrete learning material. The choice of a context is a delicate matter that requires careful reflection (Sethole, 2004). Whether a certain context functions successfully within a given situation depends on a multitude of factors. While topics can be suggested as potential sources of meaningful problems (such as in the abovementioned assessment standard), the specific mathematics that has to be mastered should always be the first priority.

We also have serious concerns regarding the speed at which learners are expected to transfer from informal to formal procedures. In this regard Drijvers (2003: 42) emphasises that "the transition from informal to formal algebra is a level jump that students find difficult to make. The lack of time spent on the informal phase and on the students' schematisation is responsible for this. Too soon strategies are shortened, automatised and condensed into compact algebraic forms." Referring to the experience in the Netherlands, Drijvers (2003: 57) continues: "Much attention is paid to the exploration of realistic situations at the referential level, to the process of horizontal mathematisation, to the translation of the problem situation into mathematics and to the development of informal problem-solving strategies. Variables, 
for example, are often labelled with words that have a direct relationship with the context from which they are taken."

Example 1: a choice between cell phones The problem of which cell phone company to choose is presented in Table 1.
There is discussion about essential mathematical issues, such as:

- the subdivision of the number lines along the horizontal and vertical axes;

- whether a straight line is the correct graph;

- how accurately the point of intersection can be read from the graph;

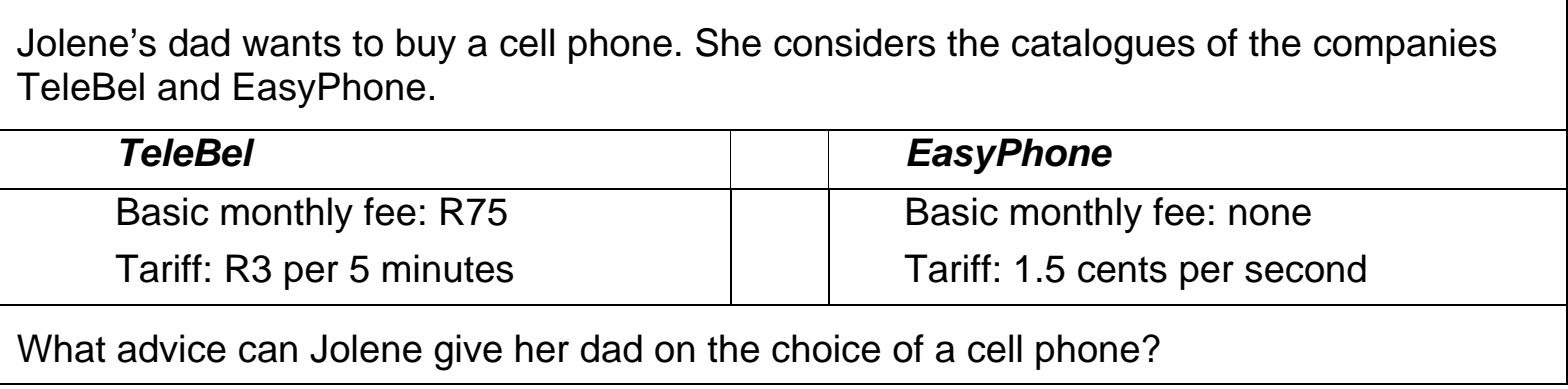

Table 1. Choice between cell phones

It seems as if this context works satisfactorily in a grade 9 class. There is discussion about seconds and minutes and about 60 cents and R0.60. What is the meaning of a basic monthly fee? With 100 minutes of airtime EasyPhone is cheaper, while TeleBel is cheaper with 500 minutes of airtime. Somewhere in between there must be a switching point. A table and a graph are produced to investigate this further (Table 2 and Figure 1). This enables Jolene to advise her dad.
- how the formula can be used to find the exact solution.

It is a real challenge to find the correct equation and to solve it. One line of argumentation is:

If $0.9 \times$ airtime $\min =75+0.6 \times$ airtime $\min$, then R75 is sufficient for 0.3 airtime minutes. Hence 0.3 $x$ airtime $\min =75$ and hence $3 x$ airtime $\min =$ 750 . The sought-after number of airtime minutes is a third of 750 . Hence for 250 minutes of airtime the cost is R225 for both companies.

\section{TeleBel}

\begin{tabular}{c||c|c|c|c|c|c|c} 
No. of minutes & 0 & 100 & 200 & 300 & 500 & 800 & 1000 \\
\hline Cost (in Rands) & 75 & 135 & 195 & 255 & 375 & 555 & 675
\end{tabular}

\section{EasyPhone}

\begin{tabular}{l||c|c|c|c|c|c|c} 
No. of minutes & 0 & 100 & 200 & 300 & 500 & 800 & 1000 \\
\hline Cost (in Rands) & 0 & 90 & 180 & 270 & 450 & 720 & 900
\end{tabular}

\section{Table 2. Comparative table (linked to Figure 1)}

This problem has a context which is very appropriate for the specific learners.

- The context fits into their field of experience. They are familiar with the concepts cell phone, basic monthly fee and airtime minutes.

- For these learners the problem is challenging. They are determined to find a solution.

- The mathematics involved in this context is relevant.

- The problem fits into their learning process.

The learners communicate in the language of the context (Table 3).
Here we do not have the routine execution of an algorithm, but rather the insightful manipulation of a formula. The learner understands throughout what it is all about.

A number of examples of this kind gradually familiarise the learner with the essential matters relating to linear functions: the form of the formula and the role of the coefficients for the gradient and the y-intercept.

\section{Context-rich mathematics}

For a developer of learner material in the spirit of 


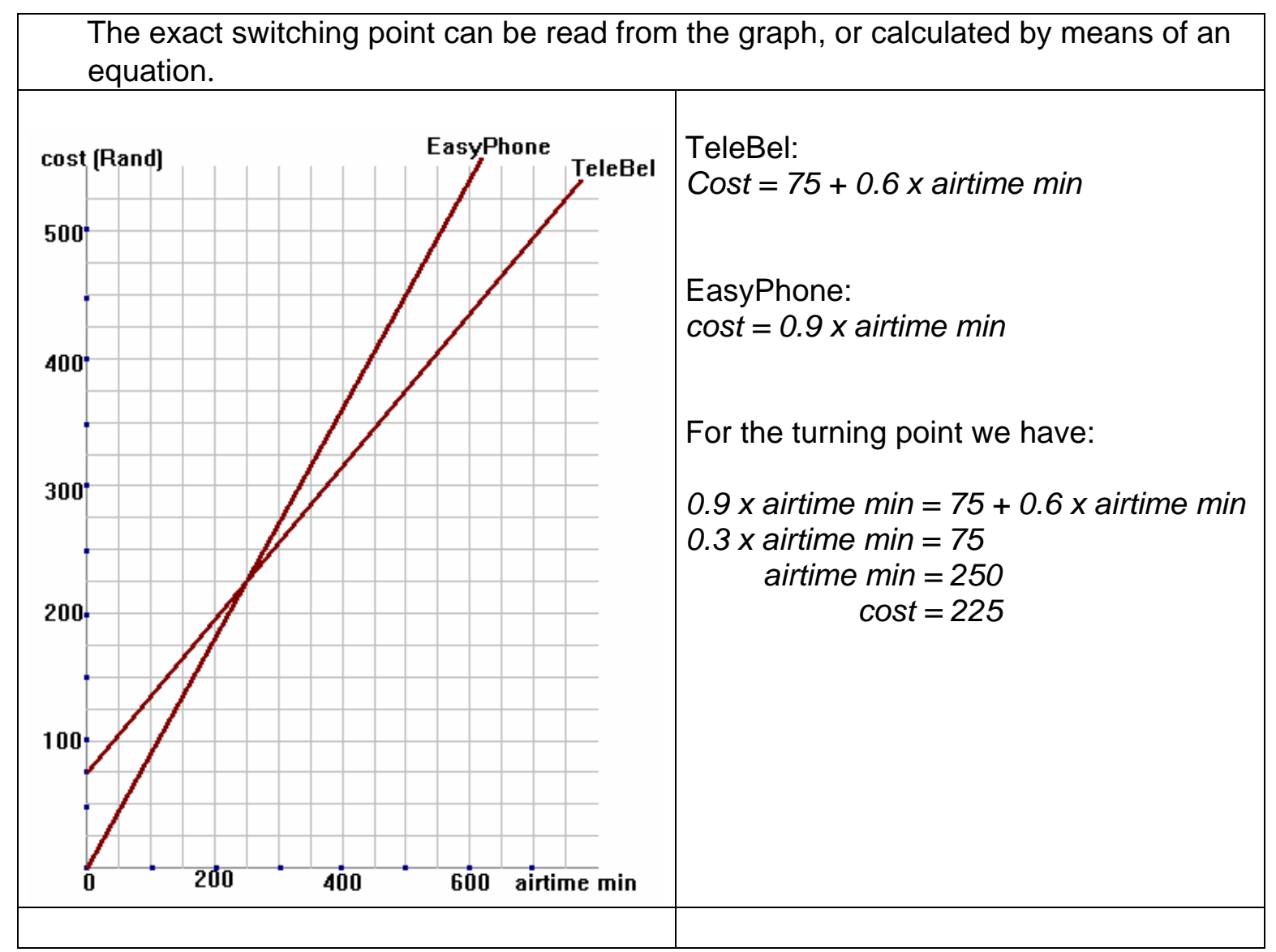

Figure 1. Comparative graph (linked to Table 2)

\begin{tabular}{|l|l|}
\hline Language of the context & Mathematical language \\
\hline \hline Airtime minutes on horizontal axis & x-axis \\
\hline Cost on vertical axis & y-axis \\
\hline Price per airtime minute & gradient \\
\hline Basic monthly fee airtime minutes the two & $\begin{array}{l}\text { Read the coordinate of a point of } \\
\text { intersection from a graph or solve an } \\
\text { equation. }\end{array}$ \\
\hline $\begin{array}{l}\text { For 250 } \\
\text { companies' tariffs are the same, viz. R225 }\end{array}$ \\
\hline $\begin{array}{l}\text { For more than 250 airtime minutes TeleBel } \\
\text { is the cheapest. }\end{array}$ & Solving an inequality \\
\hline
\end{tabular}

Table 3. Language of the context versus mathematical language

Realistic Mathematics Education, a context is not simply attractive background decoration used to illustrate mathematics. A context is purposefully chosen to teach learners how to use mathematics.
The use of mathematical subject terminology is (initially) avoided. The learner is allowed to think and speak in terms of notions within the context. 
Example 2: Interest rates

A formula to save money with $10 \%$ interest can be written as:

new capital $=$ old capital $+0.1 \times$ old capital

It is not difficult to convince learners that this can be rewritten as:

$$
\text { new capital }=1.1 \times \text { old capital }
$$

With examples of this kind there is no need to use terminology such as (common) terms, variable, coefficient and distributive law. By using words/expressions to denote variables and by avoiding the convention of omitting the multiplication sign, we make it easier for the learner to understand the formula.

In this way we gradually prepare learners in grades 7 and 8 to achieve the following assessment standard:

We know this when the learner interprets and uses the following basic algebraic vocabulary in context: term, expression, coefficient, exponent (or index), base, constant, variable, equation, formula (or rule). (Department of Education, 2002: 79)

In grade 9 mathematical sentences such as the following can then be comprehended:

$$
\begin{aligned}
& \text { For all numbers } a \text { we have: } \\
& 5 \times a-3 \times a=2 \times a ! \\
& \text { For which number } a \text { do we have: } \\
& 5 \times a+12=3 \times a+18 \text { ? }
\end{aligned}
$$

A clear distinction is made between a rewriting rule and an equation.

\section{Learning Outcome 1: numbers, operations and relationships}

There are learning outcomes that originate from the mathematical needs of earlier generations, but that are less relevant for the workaday life of someone who lives in the $21^{\text {st }}$ century. Calculation with fractions is such a topic and it creates problems for the learners. The curriculum for the senior phase prescribes calculations with fractions as follows:

The range of numbers developed by the end of grade 9 is the set of rational numbers. In this phase, the learner should:

- be given ample opportunity to solve a variety of problems, using an increased range of numbers and the ability to perform multiple operations correctly and fluently.

(Department of Education, 2002: 62)
The assessment standards for grade 7 specify, among other things:

We know this assessment standard has been met when the learner estimates and calculates by selecting and using operations appropriate to solving problems that involve: addition, subtraction and multiplication of common fractions. (Department of

Education, 2002: 70)

In this regard Moss (2005: 309) remarks: "In fact, the rational-number system poses problems not only for youngsters, but for many adults as well."

In everyday life calculations with fractions have become outdated. Calculations with fractions are done in decimal form. In our opinion learners need not be troubled with calculations such as:

$$
\frac{1}{2}+\frac{1}{3}=\frac{3}{6}+\frac{2}{6}=\frac{5}{6}
$$

We prefer to emphasise the concept that: a fraction is a number. In this regard it is then important to let learners reflect on phrases such as:

You pay half of one half.

We give $25 \%$ discount.

Take two, pay only for one.

If you buy for R1.50, you only pay R1.00.

Take three, pay only for two.

The important ideas are the fraction as a number, its position on the number line and the equivalent decimal notation. Calculations with fractions are restricted to calculations with the equivalent decimal numbers. This is also relevant in everyday life.

Much attention should also be paid to the concept of a fraction as a ratio. Learners can solve many practical problems by making use of a socalled ratio table. In a ratio table each column has to be an equivalent ratio. Learners should be familiar with the fact that they can create new columns by multiplying a column with a constant or by adding two columns. They are allowed to use as many columns as they like. For example:

A car uses 8 litres of fuel for every 100

kilometres. How far can one drive with a

full tank of 60 litres?

A calculation using a ratio table can be seen in Table 4. The conclusion is that one can drive 750 $\mathrm{km}$ with a full tank of fuel.

Another example:

60 learners have written a mathematics

test. $70 \%$ of them have passed. How

many learners have passed?

One version of a calculation using a ratio table is 


\begin{tabular}{l|c|c|c|c|c|c|c|}
\cline { 2 - 7 } No. of litres & 8 & 40 & 20 & 60 & & & \\
\hline No. of kilometres & 100 & 500 & 250 & 750 & & & \\
\cline { 2 - 9 }
\end{tabular}

Table 4. A ratio table of fuel consumption

shown in Table 5. The conclusion is that 42 learners have passed.

of a negative number. However, multiplication of negative numbers cannot be illustrated with debt as

\begin{tabular}{l|c|c|c|c|c|c|c|}
\cline { 2 - 7 } No. of learners & 100 & 10 & 20 & 30 & 40 & 50 & 60 \\
\hline No. that passed & 70 & 7 & 14 & 21 & 28 & 35 & 42 \\
\hline
\end{tabular}

Table 5. A ratio table of learner performance

Consider another example (for which a ratio table is presented in Table 6):

The floor plan of a school is drawn with a scale of $1: 200$. A passage is $12 \mathrm{~cm}$ long on the floor plan. What is the length of the passage in reality? a context. Minus five degrees times minus three degrees also does not make sense.

Example 3: A fictitious context of a witch The following idea of a fictitious context where negative numbers are applied is developed from a hint during an informal conversation with

\begin{tabular}{l|c|c|c|c|c|c|c}
\cline { 2 - 7 } $\begin{array}{l}\text { Length on the floor plan } \\
\text { (in cm) }\end{array}$ & 1 & 2 & 4 & 8 & 12 & & \\
\hline Real length (in cm) & 200 & 400 & 800 & 1600 & 2400 & & \\
\hline Real length (in m) & 2 & 4 & 8 & 16 & 24 & & \\
\cline { 2 - 9 }
\end{tabular}

Table 6. A ratio table of length of a passage

Negative numbers in school mathematics

What is true for fractions is also true for negative numbers: calculations with negative numbers never occur in everyday life. However, learners encounter formulae and the accompanying graphs where negative numbers occur, and therefore they should be familiar with calculations using negative numbers. The assessment standards for Learning Outcome 1, grade 7 specify, among other things:

We know this assessment standard has been met when the learner estimates and calculates by selecting and using operations appropriate to solving problems that involve multiple operations with integers. (Department of Education, 2002: 70)

There is no realistic context for calculations with negative numbers. Debt and temperature can be written as negative numbers. The cancelling of debt can then serve as an illustration of subtraction
Freudenthal in approximately 1975 . It uses the context of a witch and goes a long way towards meeting the objections against the use of negative numbers. The witch has a cauldron with hot (positive) and cold (negative) blocks. The witch adds blocks to the cauldron (addition) and removes blocks from the cauldron (subtraction). Learners become aware of the two-fold meaning of the plus and minus signs: addition and subtraction (add or remove blocks), on the one hand, and positive and negative (hot or cold blocks), on the other.

By working within this context, learners should become familiar with rules such as: a positive number times a negative number gives a negative number. In the end learners should routinely apply these rules. They should not memorise the rules as a recipe, but should rather be able to explain the rules. 

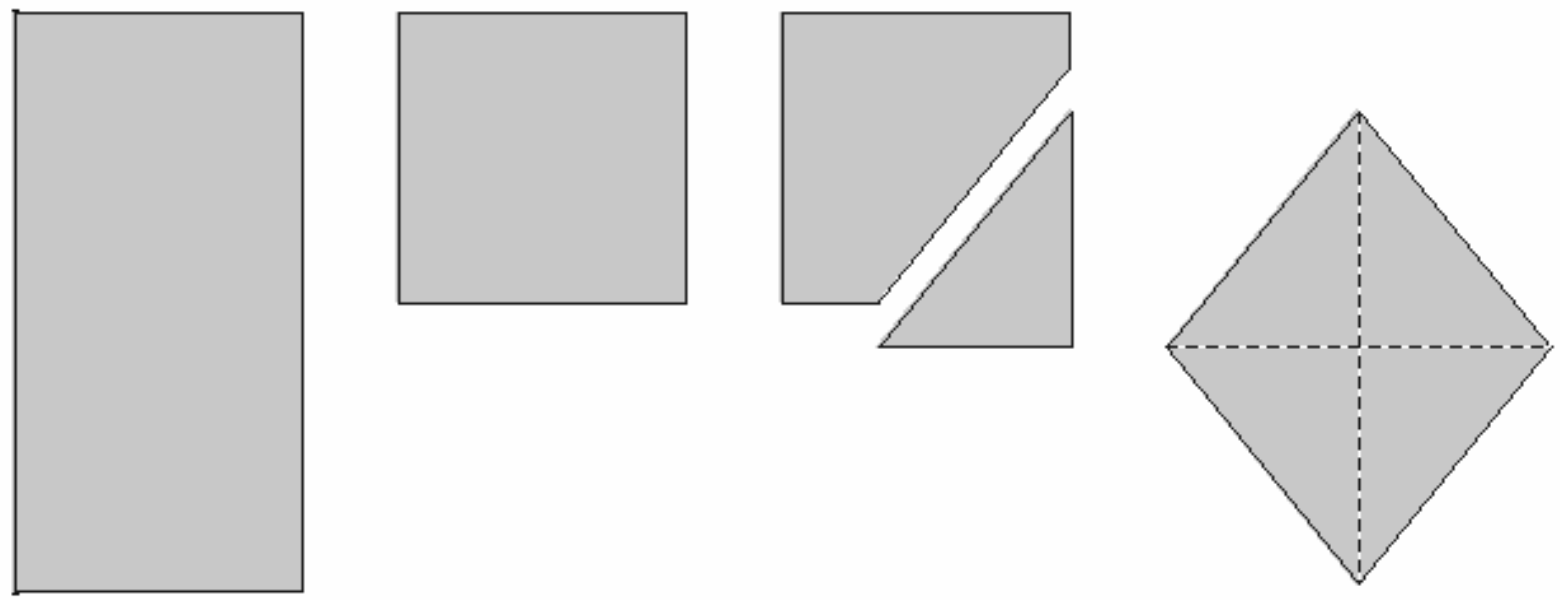

Figure 2. Paper-folding and cutting - a rhombus

Learning Outcome 3: space and shape (geometry) For mathematics tuition to learners of this age group and specifically for geometry teaching this proverb applies:

I hear and I forget

I read and I remember

I do and I understand.

For learners in our project geometry is meant to be a "doing" activity!

The curriculum specifies, among other things:

In this phase the learner draws and constructs a wide range of geometric figures and solids using appropriate geometric instruments. (Department of Education, 2002: 64)

The assessment standards for grade 9 opt for a formulation with ample use of the language of mathematics:

We know this assessment standard has been met when the learner uses transformations, congruence and similarity to investigate, describe and justify (alone and/or as a member of a group or team) properties of geometric figures and solids, including tests for similarity and congruence of triangles. (Department of Education, 2002: 83)

We regard it as possible to realise this outcome without reference to the language of mathematics.

In the next example the properties of a rhombus are conveyed through cutting and the identification of symmetries. This approach increases the chances of really comprehending the properties and not simply memorising them. The term congruence does not need to be mentioned at all.

\section{Example 4: Paper-folding and -cutting}

For this exercise you have to fold an A4 sheet of paper twice and then give it a straight cut near the double-folded corner (Figure 2). The resultant quadrilateral is called a rhombus.

The properties of the rhombus can all be deduced through the mental processes accompanying the practical activities of cutting and folding.

- The four sides have the same length, since they all fit on the cut side.

- The diagonals bisect each other, since they are the folded sides of the A4 sheet.

- The diagonals are orthogonal to each other, because the A4 sheet has right-angled corners.

- The diagonals bisect the angles, because these eight angles fit four on four after the cutting has been done.

- Therefore the opposite angles are also equal and the opposite sides are parallel.

The utilisation of similarity should precede the learning of the property that two triangles are similar when two angles are equal. For example:

\section{Example 5: Similarity}

John's measuring-rod has a length of 2 metres. At a certain stage the measuringrod has a shadow of $1.25 \mathrm{~m}$. The shadow of a streetlamp is then $3.9 \mathrm{~m}$.

Show in the sketch how the shadow is formed by sun rays.

Similarity is an enlargement or a reduction, i.e. the same form in the same proportions. The triangles formed by sun beams, objects and shadows are similar and therefore the unknown height of the streetlamp can be calculated (Figure 3 ). 


\section{Bertus van Etten and Kosie Smit}

\section{Learning Outcome 5:}

Data Handling

The curriculum specifies, among other things:

In this phase the study of chance (probability) should include both single and compound events. Through experimentation and the analysis of situations, the learner should recognise the difference between the probability of outcomes and their relative frequency in simple experiments. (Department of Education, 2002: 66)

The assessment standards for grade 9 specify:

We know this assessment standard has been met when the learner considers situations with equally probable outcomes, and determines probabilities for compound events using two-way tables and tree diagrams. (Department of Education, 2002: 91)

Before you reach the stage where learners can talk about equally probable outcomes, they should experience that probabilities as such can be determined. They are familiar with the context of gambling machines. You can create a situation of a gambling machine in class.

\section{Figure 3. Similarity - calculation of an unknown height}

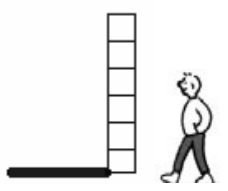

\section{Example 6: A gambling machine}

You playfully introduce a gambling machine in class. Instead of a real machine, you use three dice. The rules of this gambling machine are:

- If you throw three sixes, you win R10.

- If you throw two sixes, you win R5.

- If you throw one six, you win Rl.

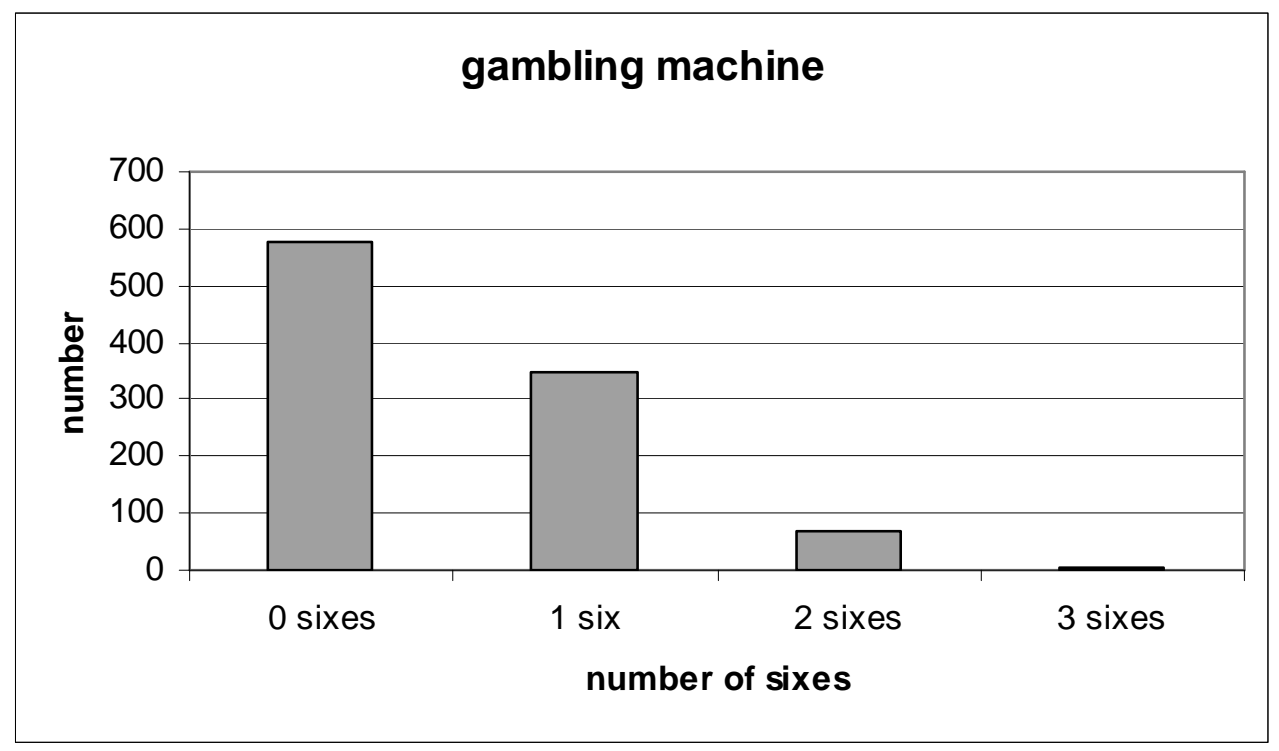

Figure 4. Gambling machine bar graph 
has the best chance of making a profit. The question should also be considered whether playing with three dice is a realistic simulation of other situations of chance, e.g. a certain kind of playing machine in a café or at a fair.

\section{Mathematisation revisited}

The context plays an essential role in the teachinglearning process. It is not only the mathematical activities that form part of the learning process, such as the gathering of information and of processing it in tables and graphs, but also the translation from context to mathematics and from the mathematical solution to an answer to the original question.
African coastline. In 1995 there were an estimated 2000 whales in South African waters. Since then the population has increased by $7 \%$ per year. An information board informs tourists that this boils down to a doubling of the population in 10 years.

\section{Mathematisation 1}

There are various ways in which this context can be translated into a mathematical model. One possibility is represented in Table 8a.

\section{Doing mathematics 1}

The table must be completed. This can hardly be done without a calculator (Table $8 \mathrm{~b}$ ).

\section{Mathematisation: the context is translated into mathematics \\ Doing maths: find a mathematical solution through mathematical activities Interpret: translate the mathematical solution to the context Verify: test whether the solution fits into the context}

Table 7. The process of problem solving

\section{Involvement with contexts}

After a context has been investigated (What does it deal with? To which question do we have to find an answer?), four activities must occur (Table 7). In a scheme, these are represented in Figure 5.

We illustrate the scheme with a final example from the field of algebra.

\section{Example 6: Whales in South African waters}

Whales appear regularly along the South

\section{Interpretation 1}

After 10 years the (rounded) number of whales has indeed doubled.

\section{Mathematisation 2}

The given situation can also be described as a formula:

number of whales $=2000 \times 1.07^{\text {year }-1995}$

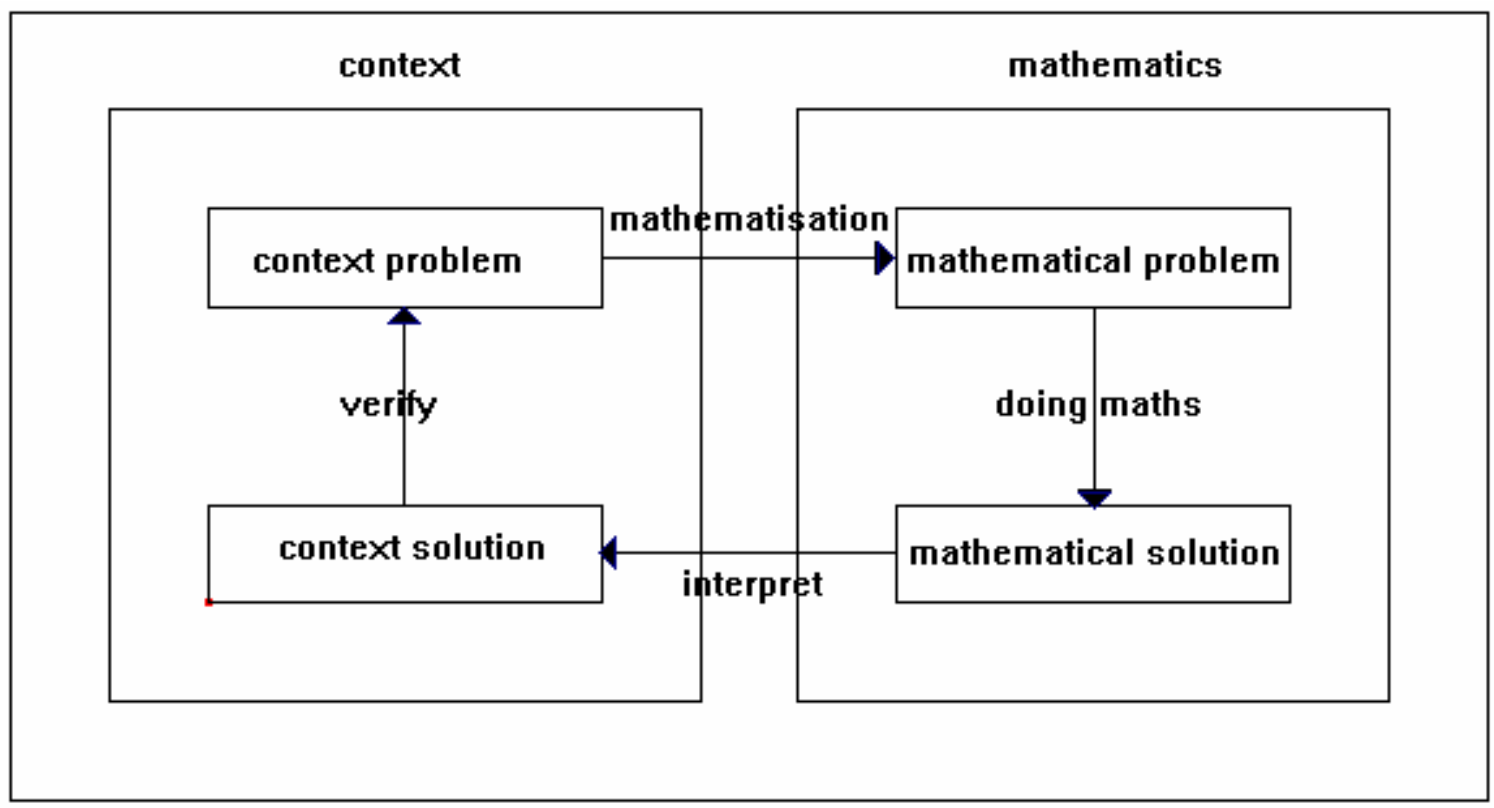

Figure 5. Scheme of learning mathematics in a context 


\begin{tabular}{|l||l|l|l|l|l|l|l|l|l|l|l|}
\hline Year & 1995 & 1996 & 1997 & 1998 & 1999 & 2000 & 2001 & 2002 & 2003 & 2004 & 2005 \\
\hline Increase & & & & & & & & & & & \\
\hline $\begin{array}{l}\text { No. of } \\
\text { whales }\end{array}$ & 2000 & & & & & & & & & & \\
\hline
\end{tabular}

Table 8a. Mathematical model of whales in South African waters

\begin{tabular}{|l||r|r|r|r|r|r|r|r|r|r|r|}
\hline Year & 1995 & 1996 & 1997 & 1998 & 1999 & 2000 & 2001 & 2002 & 2003 & 2004 & 2005 \\
\hline Increase & & 140 & 150 & 160 & 172 & 184 & 196 & 210 & 225 & 241 & 257 \\
\hline $\begin{array}{l}\text { No. of } \\
\text { whales }\end{array}$ & 2000 & 2140 & 2290 & 2450 & 2622 & 2805 & 3001 & 3212 & 3436 & 3677 & 3934 \\
\hline
\end{tabular}

Table 8b. Completed table of whales

\section{Doing mathematics 2}

Examine whether $2000 \times 1.07^{10} \approx 4000$ ?

This can be rewritten as the question: Is $1.07^{10} \approx 2$ ?

The time it takes for the population to double is not dependent on the initial number (here 2000), but on the percentage increase (here 7\%).

\section{Interpretation 2}

After 10 years the number of whales is indeed more or less double the original number, because $1.07^{10}=1.96715$.

\section{Verification}

In both cases there has to be reflection on the meaning of the mathematical results within the context. When the table was filled in, decimal numbers were rounded to natural numbers. There cannot be 2289.8 whales. But a number of 3934 whales in 2005 is also not very likely. These calculations are approximations of the real situation. The numbers 7\% and 2000 are also only estimations made by marine biologists. However, these estimations enable us to say something about the population.

In a broader perspective, the proponents of Realistic Mathematics Education describe the phases in the problem-solving process as horizontal and vertical mathematisation (Freudenthal, 1991; Gravemeijer, 1994; 1998). Drijvers (2003: 53) explains that "horizontal mathematisation concerns organising, translating, and transforming realistic problems into mathe- matical terms, in short, mathematising reality. Vertical mathematisation concerns reflection on the horizontal mathematisation from a mathematical perspective, in short, mathematising the mathematical activities and developing a framework of mathematical relations." This formulation refers not only to the solution of individual problems, but more generally to the mathematical development established through the solution of and reflection on a range of carefully selected problems.

\section{Problems with the RNCS}

The current version of the RNCS makes it difficult for a developer to choose mathematics learning material. The curriculum does not clearly indicate what balance should be established between the learning of formal mathematics, on the one hand, and learning to use mathematics, on the other. As a result, a developer of material has difficult choices to make.

By including the language of mathematics in the curriculum for grades 1 to 9 , time and energy are demanded for learning material

- that is sometimes not relevant to everyday life,

- that is mostly presented too early for the learner,

- that can only be reproduced in the format of a recipe,

- that bears no or very little intrinsic motivation.

On the contrary, learning material with the focus on using mathematics 
- can well be developed in such a way that learners experience mathematics as relevant for their lives outside the classroom,

- can well be adapted to the level of thinking of learners at their stage of development,

- can put the emphasis on the development of mathematical concepts,

- can initiate intrinsic motivation well.

We admit that, when realistic contexts are explored, learners are expected to read and interpret text consisting of a greater use of words/language. In many instances this poses a problem, since in the project schools learners' reading skills are often under-developed. However, our experience has convinced us that the desire to solve realistic problems often acts as a stimulus for learners to also improve their reading proficiency.

\section{Responses of teachers}

The following responses (translated from Afrikaans into English) of three teachers in the project schools illustrate their experience of the learning material:

The learning material poses real challenges to learners. Although I sometimes think that the examples are too difficult, the learners time and again surprise me with sensible solutions. The fact that the presentation is within context, and that the examples link to their experience (cakes, cars, etc.), makes it more understandable to the learners.

For me as an educator it was interesting to observe that the learners look forward to the mathematics lessons. In dealing with a module, all the learners were given the opportunity to discover mathematics, but also to discover themselves. The learner can see in the module what he can and cannot do. He could write down his own conclusions in his own module. The weaker learner could progress according to his own abilities, while the stronger learner could tackle the more challenging work on his own. This was really a challenge to the learners. I make bold to say that the old mathematics had a restraining effect on the learner's route of discovery.

The modules involve much reading. This creates the opportunity and motivation for learners to improve their reading. They are anxious to read. However, for the weaker learner the volume of reading matter can indeed be a problem.

On the basis of our experience we make a plea that material developers are allowed to translate the curriculum for the senior phase into context-rich mathematics and to postpone much of the language of mathematics until grades 10, 11 and 12 .

\section{References}

Drijvers, P.H.M. (2003). Learning Algebra in a Computer Algebra Environment. Utrecht: Freudenthal Institute.

Department of Education (2002). Revised National Curriculum Statement Grades $R-9$ (Schools); Mathematics, Gazette No. 23406, Vol. 443. Pretoria: Department of Education.

Freudenthal, H. (1973). Mathematics as an Educational Task. Dordrecht: Reidel.

Freudenthal, H. (1991). Revisiting Mathematics Education. Dordrecht: Kluwer Academic Publishers.

Gravemeijer, K.P.E. (1994). Developing Realistic Mathematics Education. Utrecht: Freudenthal Institute.

Gravemeijer, K. P. E. (1998). Developmental Research as a Research Method. In A. Sierpinska \& J. Kilpatrick (Eds.), Mathematics as a Research Domain: A Search for Identity. Books I and II (pp. 277-295). Dordrecht: Kluwer Academic Publishers.

Moss, J. (2005). Pipes, Tubes and Beakers: New Approaches to Teaching the Rational-Number System. In M.S. Donovan \& J.D. Bransford (Eds.), How Students Learn, History, Mathematics and Science in the Classroom (pp. 309-349). Washington DC: The National Academies Press

Sethole, G. (2004). Meaningful Contexts or Dead Mock Reality: Which Form Will the Everyday Take? Pythagoras, 59, 18-25. 